\title{
SYNTHESIS AND SPECTRAL STUDIES OF ORGANOTIN(IV) COMPLEXES WITH BIFUNCTIONAL TETRADENTATE SCHIFF BASES
}

\author{
H. L. Singh and A. K. Varshney* \\ Department of chemistry, University of Rajasthan, Jaipur-302004, India
}

\begin{abstract}
Coordination compounds formed by the interaction of metal ion with several potentially tetradentate ligands [N,N'-bis(salicylaldehyde)2,6-diaminopyridine, N,N'-bis(2-hydroxy-1-naphthaldehyde)- 2,6diaminiopyridine, N,N'-bis(benzoin)2,6-diaminopyridine] have been prepared. Stoichiometries of the complexes have been established by metal, carbon, hydrogen and nitrogen analysis and molecular weights, conductivity measurements, UV, IR and nuclear magnatic resonance $\left({ }^{1} \mathrm{H},{ }^{13} \mathrm{C}\right.$ and $\left.{ }^{119} \mathrm{Sn} N M R\right)$ spectral Studies. The tentative coordination numbers and stereochemical environments around organotin(IV) are discussed in each case.

Introduction

The study of coordination compounds has expanded rapidly and in many diverse fields. The synthesis of organotin(IV) derivatives of the ligands have the donor systems, ON. ONO and ONS has been reported from these laboratories [1-8]. In this paper we report the synthesis and characterization of some organotin(IV) derivatives of bifunctional tetradentate ligands with ONNO as the donor sequence. The complexes have been prepared by the reaction of dibutyltin oxide and dimethyltin dichloride with these tetradentate ligands.
\end{abstract}

\section{Material and Methods}

All necessary precautions were observed to exclude oxygen and moisture during the synthesis and handling of the compounds. Anal.R. grade chemicals were used as received for all experiments. The melting points were determined on a Toshniwal cappillary melting-point apparatus. Tin was estimated gravimetrically as $\mathrm{SnO}_{2}$ and nitrogen was estimated by kjeldahl's method [9-10]. Infra-red spectra were recorded on a Perkin Elmer $577 \mathrm{IR}$ spectrophtometer in the region $4000-200 \mathrm{~cm}^{-1}$ using $\mathrm{KBr}$ optics. ${ }^{1} \mathrm{H},{ }^{13} \mathrm{C}$ NMR and ${ }^{119} \mathrm{Sn} N M R$ spectra have been recorded in $\mathrm{CDCl}_{3}$ and $\mathrm{CHCl}_{3}$ solution, respectively on a Jeol $\mathrm{FX}-90 \mathrm{Q}$ spectrometer. TMS has been used as an internal reference for ${ }^{1} \mathrm{H}$ or ${ }^{13} \mathrm{C} \mathrm{NMR}$. For ${ }^{119} \mathrm{Sn}$ NMR, tetramethyltin (TMT) has been used as an external reference. Molar conductance measurements were made in anhydrous DMF at $36 \pm 1^{\circ}$ $\mathrm{C}$ using a Systronic conductivity bridge Model-305. Molecular weight determinations were carried out by the Rast camphor method.

Synthesis of ligands

$\mathrm{N}, \mathrm{N}$-bis(salicylaldehyde)2,6-diaminopyridine[BSDAPH ${ }_{2}, \mathrm{~N}, \mathrm{~N}$-bis(2-hydroxy-1-naphthaldehyde)2,6diamino- pyridine[BHNDAPH$\left.H_{2}\right], \mathrm{N}, \mathrm{N}$-bis(benzoin)2,6-diaminopyridine [BBDAPH ${ }_{2}$ ] were prepared by condensation of 2,6-diaminopyridine with salicylaldehyde, 2-hydroxy-1-naphthaldehyde or benzoin in 1:2 molar ratio in the medium of ethanol. The contents were refluxed for two hours. The solid ligands were separated out and dried under reduced pressure. There were purified by recrystallization from the same solvent. These were analyzed for $\mathrm{C}, \mathrm{H}, \mathrm{N}$ before use. The structures of the ligands as shown below.<smiles>Oc1ccccc1/C=N/c1cccc(/N=C/c2ccccc2O)n1</smiles>

$\mathrm{BSDAPH}_{2}$<smiles>Oc1ccc2ccccc2c1C=Nc1cccc(N=Cc2c(O)ccc3ccccc23)n1</smiles>

BHNDAPH:

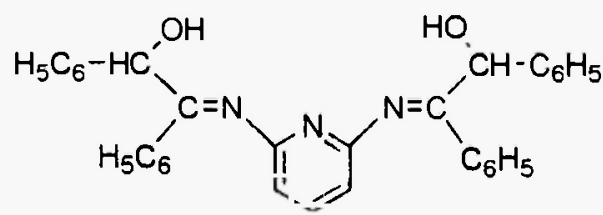

$\mathrm{BBDAPH}_{2}$ 
1. $\quad$ BSDAPH ${ }_{2}$ : Yield $82 \%$; Mol. Wt. $[F(C)]$ : $306(317)$; yellow solid; M.P. 245 (d) ${ }^{\circ} \mathrm{C}$; Analysis $[\% \mathrm{~F}(\mathrm{C})]$ C. $71.69(71.89) ; \mathrm{H}, 4.70(4.77) ; \mathrm{N}, 13.18(13.25) ; \mathrm{IR}\left(\mathrm{cm}^{-1}\right): v(\mathrm{C}=\mathrm{N}), 1618, v(\mathrm{C}-\mathrm{O}), 1282, v(\mathrm{OH}) 2880-2720$ ${ }^{1} \mathrm{H}$ NMR $(\delta \mathrm{ppm}): 7.46-6.80,[\mathrm{~m}, 11 \mathrm{H}($ Arom. $)] ; 8.20,[\mathrm{~s}, 2 \mathrm{H}(\mathrm{CH}=\mathrm{N})] ; 13.20,[\mathrm{~s}, 2 \mathrm{H}(\mathrm{OH})] ;{ }^{13} \mathrm{C}$ NMR $(\delta \mathrm{ppm})$ $\mathrm{C}\left(2 / 2^{\prime}\right)-\mathrm{OH}, 156.4 ; \mathrm{C}\left(7 / 7^{\prime}\right)=\mathrm{N}, 166.2$, Arom. carbons: $\mathrm{C}\left(1 / 1^{\prime}\right) 116.9, \mathrm{C}\left(3 / 3^{\prime}\right) 114.5, \mathrm{C}\left(4 / 4^{\prime}\right) 129.2, \mathrm{C}\left(4 / 4^{\prime}\right) 120.2$, $\mathrm{C}\left(6 / 6^{\prime}\right) 126.7, \mathrm{C}\left(8 / 8^{\prime}\right) 154.6, \mathrm{C}\left(9 / 9^{\prime}\right) 120.8, \mathrm{C}(10) 136.6$

2. BHNDAPH 2 : Yield $88 \%$; Mol. Wt. [F(C)]: $410(417)$; brownish yellow solid; M.P. $278^{\circ} \mathrm{C}$; Analysis: $[\% \mathrm{~F}(\mathrm{C})]$ : $\mathrm{C}, 77.5(77.66) ; \mathrm{H}, 4.50(4.59) ; \mathrm{N}, 10.00(10.07) ; \mathrm{IR}\left(\mathrm{cm}^{-1}\right): v(\mathrm{C}=\mathrm{N}), 1615, v(\mathrm{C}-\mathrm{O}), 1280, v(\mathrm{OH})$ 2890-2700; ${ }^{1} \mathrm{H}$ NMR $(\delta \mathrm{ppm}): 7.50-6.80,[\mathrm{~m}, 15 \mathrm{H}$ (Arom.)]; 8.25, [s, $2 \mathrm{H}(\mathrm{CH}=\mathrm{N})] ; 13.40,[\mathrm{~s}, 2 \mathrm{H}(\mathrm{OH})] ;{ }^{13} \mathrm{C}$ NMR $(\delta \mathrm{ppm}) ;(\mathrm{C}-\mathrm{OH}), 160.2 ;(\mathrm{C}=\mathrm{N}), 168.2$, Arom. carbons: $117.1,120.1,129.5,128.2,122.3,153.6,122.6$, $148.8,121.4,137.9$.

3. $\quad$ BBDAPH $_{2}$ : Yield $85 \%$; Mol. Wt. $[\mathrm{F}(\mathrm{C})]$ ] $483(497)$; gray solid; M.P. $120^{\circ} \mathrm{C}$; Analysis $[\% \mathrm{~F}(\mathrm{C})]$ : $\mathrm{C}$ $79.72(79.64) ; \mathrm{H}, 5.41(5.47) ; \mathrm{N}, 8.40(8.45) ; \mathrm{IR}\left(\mathrm{cm}^{-1}\right): v(\mathrm{C}=\mathrm{N}), 1620, v(\mathrm{C}-\mathrm{O}), 1285, v(\mathrm{OH}) 2900-2720 ;{ }_{1} \mathrm{H}$ NMR ( $\delta \mathrm{ppm}): 7.90-6.55,[\mathrm{~m}, 23 \mathrm{H}($ Arom. $)] ; 12.80,[\mathrm{~s}, 2 \mathrm{H}(\mathrm{OH})]$;

Synthesis of $\mathrm{Me}_{2} \mathrm{Sn}$ (IV) complexes

To a weighed amount of $\mathrm{Me}_{2} \mathrm{SnCl}_{2}$ was added the calculated amount of the ligand and triethylamine in a 1:2:2 molar ratio, using dry THF as the reaction medium in an oxygen free atmosphere. The colouir of the contents immediately changed with the precipitation of triethylamine hydrochloride. The solution was stirred on a magnetic stirrer for about $1 \mathrm{~h}$. The precipitate of triethylamine hydrochloride was filtered off and rejected. The excess solvent was removed from the filtrate and the compound was finally dried in vacuo at both temperature of $40 \pm 5^{\circ} \mathrm{C}$ after being repeatedly washed with dry cyclohexane.

Synthesis of $\mathrm{Bu}_{2} \mathrm{Sn}(\mathrm{IV})$ complexes

$\mathrm{Bu}_{2} \mathrm{SnO}$ was dissolved in dry benzene and the requisite amount of ligand was added. The contents were refluxed on a fractionating column for about $6 \mathrm{~h}$. The water liberated in the reaction was removed azeotropically with benzene. On completion of the reactions, the resulting products were rendered free from the solvent and then washed repeatedly with dry cyclohexane. The products so formed were finally dried in vacuo at $40 \pm 10^{\circ} \mathrm{C}$ for $2-3 \mathrm{~h}$. and these compounds were purified and recrystallized by anhydrous benzene. The purity of these compluxes was further checked by thin layer chromatography on silica gel $G$. The pertinent data for these compounds and other derivatives are listed below:

Compound 1. $\mathrm{Bu}_{2} \mathrm{Sn}(\mathrm{BSDAP})$ : Yield 78\% ; Mol. Wt. $[\mathrm{F}(\mathrm{C})]$ : 533 (547); dark brown solid ; M.P. $260^{\circ} \mathrm{C}$; Analysis $[\% \mathrm{~F}(\mathrm{C})]$ : $\mathrm{C}, 59.20(59.13) ; \mathrm{H}, 5.66(5.70) ; \mathrm{N}, 7.50(7.67) ; \mathrm{Sn}, 21.50(21.66) ; \mathrm{IR}\left(\mathrm{cm}^{-1}\right): v(\mathrm{C}=\mathrm{N}), 1635$, $v(\mathrm{C}-\mathrm{O}), 1300, v(\mathrm{Sn} \mathrm{N}), 420, v(\mathrm{Sn}-\mathrm{O}), 545 ;{ }^{1} \mathrm{H}$ NMR $(\delta \mathrm{ppm}): 6.80-7.50,[\mathrm{~m}, 11 \mathrm{H}$ (Arom.)]; $8.32,[\mathrm{~s}, 2 \mathrm{H}(\mathrm{CH}=\mathrm{N}]$; $0.50-1.92$, [m. $18 \mathrm{H}$ (butyl)]; ${ }^{13} \mathrm{C} \operatorname{NMR}(\delta \mathrm{ppm}): \mathrm{C}\left(2 / 2^{\prime}\right)-\mathrm{O}, 149.2 ; \mathrm{C}\left(7 / 7^{\prime}\right)=\mathrm{N}, 161.2 ;$ Arom. carbons: $C\left(1 / 1^{\prime}\right) 117.1, C\left(3 / 3^{\prime}\right) 114.6, C\left(4 / 4^{\prime}\right) 129.9, C\left(5 / 5^{\prime}\right) 120.3, C\left(6 / 6^{\prime}\right) 127.0, C\left(8 / 8^{\prime}\right) 148.9, C\left(9 / 9^{\prime}\right) 121.7, C(10) 140.4$; (Sn-Bu), 13.6,26.0,27.4,29.3; nJ(119Sn, $\left.{ }^{13} \mathrm{C}\right) \mathrm{Hz},(n=1: 915.2 ; n=2: 50.8 ; n=3 ; 173.1) ; 119 \mathrm{Sn} \operatorname{NMR}(\delta \mathrm{ppm}):-310$. Compound 2. $\mathrm{Me}_{2} \mathrm{Sn}(\mathrm{BSDAP}$ ): Yield $72 \%$; Mol. Wt. [F(C)]: 460(465); brown semi-solid; Analysis [\%F(C)] C, 54.00(54.10); $\mathrm{H}, 4.00(4.11) ; \mathrm{N}, 9.00(9.11) ; \mathrm{Sn}, 25.40(25.47) ; \mathrm{IR}\left(\mathrm{cm}^{-1}\right): v(\mathrm{C}=\mathrm{N}), 1635 ; v(\mathrm{C}-\mathrm{O}), 1305$; $v(\mathrm{Sn}-\mathrm{O}), \quad 540, v(\mathrm{Sn} \leftarrow \mathrm{N}), 425 ;{ }^{1} \mathrm{H}$ NMR $(\delta \mathrm{ppm}): 6.76-7,45,[\mathrm{~m}, 11 \mathrm{H}($ Arom.) $] ; \quad 8.36,[\mathrm{~s}, 2 \mathrm{H}(\mathrm{CH}=\mathrm{N})] ;$ 1.12, [s, $6 \mathrm{H}(\mathrm{Sn}-\mathrm{Me})] ; 2 \mathrm{~J}(119 \mathrm{Sn}, 1 \mathrm{H}) 98.4 \mathrm{~Hz},{ }^{13} \mathrm{C}$ NMR $(\delta \mathrm{ppm}): \mathrm{C}\left(2 / 2^{\prime}\right)-0,148.4, \mathrm{C}\left(7 / 7^{\prime}\right)=\mathrm{N}$, 160.1, Arom. carbons: $C\left(1 / 1^{\prime}\right) 116.9, C\left(3 / 3^{\prime}\right) 115.4, C\left(4 / 4^{\prime}\right) 130.2, C\left(5 / 5^{\prime}\right) 126.4, C\left(6 / 6^{\prime}\right) 126.8, C\left(8 / 8^{\prime}\right) 149.6, C\left(9 / 9^{\prime}\right) 121.9$, $\mathrm{C}(10) 141.0 ;(\mathrm{Sn}-\mathrm{Me}), 7.2 ; \mathrm{nJ}\left({ }^{119} \mathrm{Sn},{ }^{13} \mathrm{C}\right) 940.5 \mathrm{~Hz},{ }^{119} \mathrm{Sn} \mathrm{NMR}(8 \mathrm{ppm}):-280$.

Compound 3. $\mathrm{Bu}_{2} \mathrm{Sn}(\mathrm{BHNDAP})$ : Yield $85 \%$; Mol. Wt [F(C)]: $636(647)$; brown solid; M.P. 288 (d) ${ }^{\circ} \mathrm{C}$ Analysis $[\% \mathrm{~F}(\mathrm{C})]: \mathrm{C}, 64.75(64.81) ; \mathrm{H}, 5.40(5.44) ; \mathrm{N}, 6.40(6.48) ; \mathrm{Sn}, 18.20(18.32) ; \mathrm{IR}\left(\mathrm{cm}^{-1}\right): v(\mathrm{C}=\mathrm{N}), 1635, v(\mathrm{C}-$ O), 1305, $v(\mathrm{Sn} \leftarrow \mathrm{N}), 425, v(\mathrm{Sn}-\mathrm{O}), 545 ;{ }^{1 \mathrm{H}} \mathrm{NMR}(\delta \mathrm{ppm}): 6.90-8.12,[\mathrm{~m}, 15 \mathrm{H}$ (Arom.)]; $8.35,[\mathrm{~s}, 2 \mathrm{H}(\mathrm{CH}=\mathrm{N}), 0.52-$ 1.95, [m, $18 \mathrm{H}$ (butyl)]; ${ }^{13} \mathrm{C} \operatorname{NMR}(\delta \mathrm{ppm}):(\mathrm{C}-\mathrm{O}), 150.1,(\mathrm{C}=\mathrm{N}), 160.7$, Arom. carbons: $117.4,119.1,129.3$, $128.4,121.8,133.0,122.5,148.2,122.2,139.8 ;(S n-B u), 14.2,26.2,27.1,29.0 ; n J\left(119 S n,{ }^{13} \mathrm{C}\right) \mathrm{Hz},(n=1: 909.6$; $n=2: 47.5 ; n=3: 160.3) ;{ }^{119}$ Sn NMR $(\delta p p m):-285$.

Compound 4. $\mathrm{Me}_{2} \mathrm{Sn}(\mathrm{BHNDAP})$ : Yield 75\%; Mot. Wt. $[\mathrm{F}(\mathrm{C})]$ : $555(565)$; brown semi-solid; Analysis [\%F(C)]: C, 61.62(61.49); H, 4.02(4.10); N, 7.40(7.46); Sn $20.85(20.97) ; \mathrm{IR}\left(\mathrm{cm}^{-1}\right): v(\mathrm{C}=\mathrm{N}), 1630, v(\mathrm{C}-\mathrm{O}), 1300, v(\mathrm{Sn}-$ O), 550, $v(\mathrm{Sn} \leftarrow \mathrm{N}), 422 ;{ }^{1} \mathrm{H} \mathrm{NMR}(\delta \mathrm{ppm}): 6.95-8,10,[\mathrm{~m} .15 \mathrm{H}($ Arom. $)] ; 8.30,[\mathrm{~s}, 2 \mathrm{H}(\mathrm{CH}=\mathrm{N})] ; 1.15,[\mathrm{~s}, 6 \mathrm{H}(\mathrm{Sn}-\mathrm{Me})]$; ${ }^{13} \mathrm{C} \operatorname{NMR}(\delta \mathrm{ppm}):(\mathrm{C}-\mathrm{O}), 149.5,(\mathrm{C}=\mathrm{N}), 163.2$, Arom. carbons: $15.8,119.9,129.0,128.2,122.0,133.3$, $122.4,149.6,121.9,140.9 ;(\mathrm{Sn}-\mathrm{Me}), 8.1,{ }^{1}\left({ }^{119} \mathrm{Sn},{ }^{13} \mathrm{C}\right) \mathrm{Hz}, 950.4 ; 119 \mathrm{Sn} \mathrm{NMR}(\delta \mathrm{ppm}) ;-280$.

Compound 5. $\mathrm{Bu}_{2} \mathrm{Sn}(\mathrm{BBDAP})$ : Yield $75 \%$; Mol. Wt. $[\mathrm{F}(\mathrm{C})]$ : $710(728)$; brown solid; M.P. $165^{\circ} \mathrm{C}$; Analysis $[\% \mathrm{~F}(\mathrm{C})]: \mathrm{C}, 67.50(67.58) ; \mathrm{H}, 5.89(5.95) ; \mathrm{N}, 5.70(5.77) ; \mathrm{Sn}, 16.27(16.30) ; \mathrm{IR}\left(\mathrm{cm}^{-1}\right): v(\mathrm{C}=\mathrm{N}), 1635, v(\mathrm{C}-$ O), $1300, v(\mathrm{Sn} \mathrm{N}), 430, v(\mathrm{Sn}-\mathrm{O}), 560 ;{ }^{1} \mathrm{H}$ NMR $(\delta \mathrm{ppm}): 6.75-8.20,[\mathrm{~m}, 23 \mathrm{H}($ Arom. $)] ; 0.45-1.90,[\mathrm{~m}, 18 \mathrm{H}(\mathrm{Sn}-\mathrm{Bu}]$; ${ }_{13} \mathrm{C} \operatorname{NMR}(\delta \mathrm{ppm}): \mathrm{CH}-\mathrm{O}, 70.8$; $(\mathrm{C}=\mathrm{N}), 158.1$, Arom. carbons: $134.0,133.8,124.8,124.9,128.9,125.2$, $147.8,121.9,138.6 ;(\mathrm{Sn}-\mathrm{Bu}), 13.8,27.1,26.6,28.3 ; 119 \mathrm{Sn} \mathrm{NMR}(\delta \mathrm{ppm}):-295$.

Compound 6. $\mathrm{Me}_{2} \mathrm{Sn}(\mathrm{BBDAP})$ : Yield 78\%; MolWt. $[\mathrm{F}(\mathrm{C})]: 652(645)$; brown semi-solid; Analysis (\%F(C)]:C, $64.96(65.02) ; \mathrm{H}, 4.80(4.84) ; \mathrm{N}, 6.50(6.57) ; \mathrm{Sn}, 18.30(18.37) ; \mathrm{IR}\left(\mathrm{cm}^{-1}\right): v(\mathrm{C}=\mathrm{N}), 1630, v(\mathrm{C}-\mathrm{O}), 1310, v(\mathrm{Sn}-$ O), 550, $v(\mathrm{Sn} \leftarrow \mathrm{N}), 425 ;{ }^{1} \mathrm{H}$ NMR $(\delta \mathrm{ppm}): 6.78-8.12$, [m, $23 \mathrm{H}($ Arom.) $] ; 1.02,[\mathrm{~s}, 6 \mathrm{H},(\mathrm{Sn}-\mathrm{Me})] ;{ }^{2} \mathrm{~J}\left({ }^{119} \mathrm{Sn},{ }^{1} \mathrm{H}\right) 98 \mathrm{~Hz}$; ${ }_{13} \mathrm{C} \operatorname{NMR}(\delta \mathrm{ppm}): \mathrm{CH}-\mathrm{O}, 72.7 ;(\mathrm{C}=\mathrm{N}), 156.5$, Arom. carbons: $133.1,133.3,124.8,124.9,129.7,125.7$, 147.6, 122.8, 139.3; (Sn-Me), 8.4, ${ }^{1} \mathrm{~J}\left({ }^{119} \mathrm{Sn},{ }^{13} \mathrm{C}\right) \mathrm{Hz}$, ${ }^{119} \mathrm{Sn}$ NMR $(\delta \mathrm{ppm}):-270$. 


\section{Results and discussion}

The reactions have been used to prepare the organotin(IV) complexes, treatment of dibutyltin(IV) oxide with the ligands in dry benzene or reaction of dimethyltin dichloride with the ligands (presence of $\mathrm{Et}_{3} \mathrm{~N}$ ) in dry tetrahydrofuran solution.

$$
\begin{aligned}
& \mathrm{Bu}_{2} \mathrm{SnO}+\mathrm{LH}_{2}-\text { Dry benzene } \longrightarrow \text { Dry THF } \longrightarrow \\
& \begin{array}{l}
\mathrm{Me}_{2} \mathrm{SnCl}_{2}+\mathrm{LH}_{2}+2 \mathrm{Et}_{3} \mathrm{~N} \\
\text { (where L=dianions of Schiff bases) }
\end{array}
\end{aligned} \begin{aligned}
& \mathrm{Bu}_{2} \mathrm{SnL}+\mathrm{H}_{2} \mathrm{O} \\
& \mathrm{Me}_{2} \mathrm{SnL}+2 \mathrm{Et}_{3} \mathrm{~N} . \mathrm{HCl}
\end{aligned}
$$

The newly synthesised brown to dark brown coloured solids or semi-solids complexes are stable towards free atmospheric oxygen and moisture. The elemental analysis correspond to $R_{2} S n L$ stoichiometry with the Schiff bases present in their dianionic form. The low molar conductance value $\left(10-18 \Omega^{-1} \mathrm{~cm}^{-2} \mathrm{~mol}^{-1}\right)$ reveal the nonelectrolytic nature of all the complexes. The molecular weights of the complexes determined by the Rast camphor method correspond with the formula weight indicating their monomeric nature.

Electronic Spectra

The electronic spectra of the ligands show a $1 \mathrm{~B}$ band of the phenyl ring at $220 \pm 3 \mathrm{~nm}$. This band of high intensity shifts slightly towards higher wave length at $228 \pm 5 \mathrm{~nm}$ on complex formation. The spectra of ligands as well as the complexes show the broad bands in the regions $288-320 \mathrm{~nm} \mathrm{320-350} \mathrm{nm} \mathrm{due} \mathrm{to} \mathrm{the} \pi$ $\pi^{*}(>\mathrm{C}=\mathrm{N}-)$ transition of the chromophore and the secondary band of the benzene ring, respectively. Further, a few sharp band were observed in the region $245-275 \mathrm{~nm}$ in the spectra of the complexes, which could be assigned as charge transfer bands. It has been reported[11] that a metal is capable of forming $d \pi$-p $\pi$ bonds with ligands containing nitrogen as the donor atoms. The tin atom has its $5 \mathrm{~d}$ orbitals completely vacand and hence $L \rightarrow M$ bonding can take place by the acceptance of a lone pair of electrons from nitrogen donor atoms of the ligands.

IR Spectra

The spectra of the ligands show a broad and weak band in the region $2880-2700 \mathrm{~cm}^{-1}$ [12] which is assigned to the intramolecular hydrogen bonded $v(\mathrm{OH})$. This band disappears in the complexes indicating $v(\mathrm{Sn}-\mathrm{O})$ bond formation. The phenolic $v(\mathrm{C}-\mathrm{O})$ stretching vibrations appearing at $\sim 1280 \mathrm{~cm}^{-1}$ in the ligands undergoes a shift towards higher wave number in the complexes. This further confirm the participation of oxygen in C-O-Sn bonding[13,14]. A strong band found around at $1620 \mathrm{~cm}^{-1}$ in the ligands in attributed to the $>C=N$ stretch in view of previous assignments[15,16]. The shift of this band towards higher side (1625 \pm 7 $\mathrm{cm}^{-1}$ ) is probably due to the coordination of nitrogen to the metal atom. New bands at $\sim 420 \mathrm{~cm}^{1}$ and $\sim 545$ $\mathrm{cm}^{-1}$ may be attributed to $v(\mathrm{Sn} \leftarrow \mathrm{N})$ and $v(\mathrm{Sn}-\mathrm{O})$ bands in the complexes [14, 17]. This indicates the coordination of azomethine nitrogen to the tin atom. The ligands shows the bands observed in the region at $\sim 1600-1430 \mathrm{~cm}^{-1}$ and $700-750 \mathrm{~cm}{ }^{1}$ which is assigned to the $v \mathrm{C}=\mathrm{C}, v \mathrm{C}=\mathrm{N}$ stretching and $v \mathrm{C}-\mathrm{H}$ bending vibrations of pyridine ring remains unchanged in the spectra of complexes. No band appears in the complexes at $\sim 230 \mathrm{~cm}^{-1}$ assigned to the $v \mathrm{Sn}-\mathrm{N}(\mathrm{Py})$. This implies that the pyridine ring does not take part in complex formations

${ }^{1} \mathrm{H}$ NMR Spectra

Proton magnetic resonance spectral data of these complexes have been recorded and given in the experimental part. The signals at $\delta 12.80-13.40 \mathrm{ppm}$ in the case of ligands are due to the $\mathrm{OH}$ protons. These, however, disappear in the spectra of tin derivatives indicating the deprotonation on complexation with the tin atom. The ${ }^{1 H}$ NMR spectra of the ligands, a sharp signal is observed at $\delta \sim 8.20 \mathrm{ppm}$ due to the $-\mathrm{CH}=\mathrm{N}$ proton. It moves downfield $(\delta \sim 8.35)$ in the complexes in comparison with its original position in the ligands due to the coordination of azomethine nitrogen to the metal atom. The resonance due to the phenyl moiety remains almost unaffected in the complexes. The protons of the butyl groups appear in the range of $\delta 0.50-1.95 \mathrm{ppm}$. The methyl protons of the dimethyltin(IV) derivatives appear as a sharp singlet at $\delta 1.08 \pm$ $0.04 \mathrm{ppm}$ with $2 \mathrm{~J}\left({ }^{119} \mathrm{Sn}-1 \mathrm{H}\right)=98 \pm 1 \mathrm{~Hz}$ and multiplatets for butyl protons. The magnitude of $2 \mathrm{~J}(119 \mathrm{Sn}-1 \mathrm{H})=$ $95 \pm 1 \mathrm{~Hz}$ for other complex have been observed. The magnitude of $2 \mathrm{~J}\left({ }^{119 S \mathrm{Sn}}{ }^{1} \mathrm{H}, 98 \pm 1 \mathrm{~Hz}\right)$ is indicative of higher coordination number (>4) of tin in these complexes [18].

\section{${ }^{13} \mathrm{C}$ NMR Spectra}

In the ${ }^{13} \mathrm{C}$ NMR spectra, the shifting in the position of phenyl carbon attached to $\mathrm{OH}$ group suggests the bonding of oxygen to the tin atom. Further, the shifting of the azomethine $(>\mathrm{C}=\mathrm{N})$ carbon signal in the spectra of the complexes as compared to the ligand clearly indicates that the azomethine moiety has been involved in coordination. The ${ }^{13} \mathrm{C}, 1 \mathrm{H}$ NMR resonance are assigned by comparision with the ${ }^{13} \mathrm{C}$ NMR shifts of the ligand and the complexes of organotin(IV). The $R$ groups attached to tin display single resonance for chemically equivalent carbond, however, the butyl compounds display three resonance (resonances for two carbons being overlapped). The tin-carbon coupling ${ }^{1} \mathrm{~J}\left({ }^{119} \mathrm{Sn}-{ }^{13} \mathrm{C}\right)$ values of $\sim 940 \mathrm{~Hz}$ 
indicate the six coordination around tin is such organotin(IV) derivatives. The absolute $\mathrm{J}\left({ }^{119} \mathrm{Sn}-{ }^{13} \mathrm{C}\right)$ values in alkyltin groups usually decrease as $1 \mathrm{~J}>3 \mathrm{~J}>2 \mathrm{~J}$. These are comparable corresponding six coordinate organotin(IV) complexes[19,20].

119Sn NMR Spectra

The ${ }^{119} \mathrm{Sn}$ NMR chemical shifts of all the derivatives have been observed at $\delta-270$ to $-310 \mathrm{ppm}$ are in good agreement with the values for hexa-coordinated states around the tin atoms as reported earlier in the literature [21-23].

On the basis of the above spectral evidence, the following tentative structure can be proposed for the resulting tin complexes as shown bellow.

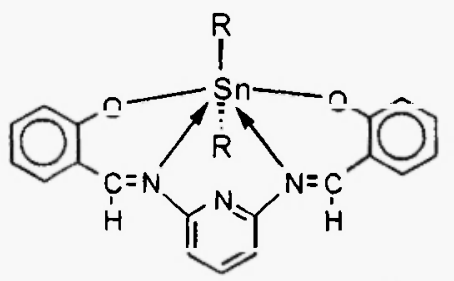

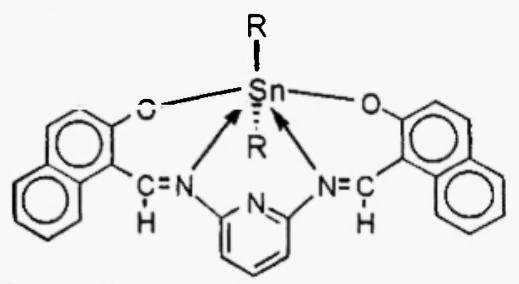

where $\mathrm{R}=-\mathrm{Me}$ or $\mathrm{n}-\mathrm{Bu}$

Acknowledgement

The authors express their sincere thanks to Professor J.P. Tandon, former Head, Department of Chemistry, University of Rajasthan, Jaipur for his helpful suggestions. One of us (H.L.Singh) thanks the CSIR, New Delhi for financial support.

\section{References}

1. A Saxena, J.P.Tandon and A.J.Crowe, Polyhedron, 4 (1985) 1085

2. R.J.Rao and H.B.Wankhede, Main Group Met. Chem., 19 (1996)4

3. R.J.Rao and H.B.Wankhede, Synth. React. Inorg Met.-Org.Chem., 25 (1995) 1049

4. B.S.Saraswat and J.Mason, Polyhedron, 5 (1986) 1449.

5. R.C.Mehrotra, G.Srivastava and B.S.Saraswat, J.Organomet. Chem., 164 (1979) 153.

6. Mala Nath and S.Goyal, Bull. Chem. Soc. Jpn., 69 (1996) 605.

7. M.Nath and R.Yadav, Bull. Chem. Soc. Jpn., 70 (1997) 1331.

8. J.S. Casas, A.Castineiras, A.Sanchez,J.Sordo, A.Vazquez-Lopez, M.C. Rodriguez-Arguells and U. Russo, Inorg. Chim. Acta, 221 (1994)61.

9. B.S.Furniss, A.J.Hannaford, P.W.G. Smith and A.R.Tatchell, 'Vogel's Text book of practical organic chemistry, $5^{\text {th }}$ ed. Longman (1989).

10. A.K. Varshney, S.Varshney and H.L.Singh, Bull.Pol.Acad. Sci. Chem., 45 (1997)373.

11. A.Saxena, J.P.Tandon, K.C.Molloy and J.J.Zuckerman, Inorg. Chim. Acta, 63(1982)71.

12. Ram A.Lal, S.Adhikari, A.Kumar and M.L.Pal, J.Indian Chem. Soc., 75(1998) 345.

13. A.K.Varshney, J.P.Tandon and A.J.Crowe, Polyhedron, 5(1986)739.

14. M.Nath.N.Sharma and C.L.Sharma, Synth. React. Inorg. Met.-Org. Chem., 21(1991)51.

15. A.K. Varshney,S.Varshney, M.Sharma and H.L.Singh, Main Group Met. Chem., $21(1998) 495$.

16. R.C.Maurya, D.D.Mishra, N.S.Rao, P. Verma and N.H.Rao, Indian J. Chem., 36A(1997)599.

17. M.Nath. and S.Goyal, Main Group Met. Chem., 16(1993) 167.

18. A.K.Gupta, S.Sharma, H.P.S.Chouhan and R.J.Rao, Synth. React. Inorg. Met.-Org. Chem., 21(1991)497.

19. T.P. Lockhart and W.F.Manders, Inorg. Chem., 25(1986)892

20. V.K.Jain, J.Mason,B.S.Saraswat and R.C.Mehrotra, Polyhedron, 4(1985)2089.

21. J..D Kennedy and W.McFarlane, Rev. Silicon, Germanium, Tin and Lead, 3(1974)235.

22. Sonika, S.Sharma, S.Gupta and A.K.Narula, Indian J. Chem., 33A(1994)1119.

23. H.C. Clark, V.K.Jain,R.C Mehrotra, B.P.Singh, G.Srivastava and T.Birchall, J.Organomet. Chem., 279(1985) 285.

Received: April 30, 1999 - Accepted: May 21, 1999 Accepted in revised camera-ready format: August 23, 1999 